\title{
REFLEXOS DA ESCRITA DE SI EM CRÔNICA DE TARSILA DO AMARAL
}

\section{REFLECTIONS OF SELF-WRITING IN CHRONICLE OF TARSILA DO AMARAL}

\author{
Valnikson Viana de OLIVEIRA ${ }^{1}$ \\ Maria Claurênia Abreu de Andrade SILVEIRA ${ }^{2}$
}

\begin{abstract}
Resumo: O presente artigo propõe uma análise da produção cronista de Tarsila do Amaral (1886-1973), uma das figuras centrais da arte brasileira no século XX, em aproximação com a escrita de si e a presença feminina na imprensa brasileira. Para isso, tomamos como foco o texto "Tragédia parisiense", publicado em 1937 pela artista plástica nos periódicos Diário de S. Paulo e $O$ Jornal, acreditando que a autora utiliza o exercício da memória como interessante artifício de atração e envolvimento de seus leitores. Dessa forma, para embasar o nosso estudo, valemo-nos de Amaral (2001; 2003), Candido (1992), Figueiredo (2013) e Gomes (2004), entre outros, assimilando aspectos da representação autobiográfica e avaliando seus desdobramentos na tessitura da crônica tarsiliana.
\end{abstract}

Palavras-Chave: Tarsila do Amaral. Crônica. Escrita de si. Autoria feminina. Imprensa brasileira.

\begin{abstract}
This paper analyses the chronicle production by Tarsila do Amaral (1886-1973), one of the central figures of Brazilian art in the 20th century, in approximation with the possibilities of self-writing and the presence of women in the Brazilian press. We focus on "Tragédia parisiense", published by this plastic artist in 1937 in the periodicals Diário de S. Paulo and O Jornal, believing that she used the exercise of memory as an interesting device to attract and involve her readers. Thus, Amaral (2001; 2003), Candido (1992), Figueiredo (2013) and Gomes (2004), among others, were used as the basis for this study, assimilating aspects of the autobiographical representation and evaluating its unfolding in the structure of Tarsila's chronicle.
\end{abstract}

Keywords: Tarsila do Amaral. Chronic. Self-writing. Female author. Brazilian press.

\section{Introdução}

A pesquisa envolvendo o suporte periódico aponta a literatura como um reflexo da condição política, da situação econômica, da organização social e do nível cultural de um país ou de um determinado período. Nesta perspectiva, para Lajolo e Zilbermam (1998), a presença literária em jornais e revistas, através dos mais diversos gêneros, garantiu um público leitor e serviu para a consolidação da arte escrita no Brasil.

\footnotetext{
${ }^{1}$ Doutorando em Letras pela Universidade Federal da Paraíba (UFPB). valnikson18@ hotmail.com

${ }^{2}$ Doutora em Letras pela Universidade Federal da Paraíba (UFPB). Professora associada da mesma instituição, vinculada ao Departamento de Metodologia da Educação. claurenia@gmail.com
} 
A crônica é o único gênero literário elaborado exclusivamente em vinculação à imprensa. Trata-se de um texto que se utiliza de linguagem informal e conotativa para narrar fatos e acontecimentos cotidianos, deixando espaço para manifestações de opinião e sentimentos acerca de algum tema. Caracterizado pela abordagem leve, agrada e possibilita certa proximidade entre quem o escreve e quem o lê, uma vez que mantém a periodicidade de produção e a atualidade crítica. Inicialmente, a crônica era apenas um relato ou registro de acontecimentos ocorridos em qualquer lugar, ou seja, uma narração de fatos localizados temporalmente. Essa relação entre memória e tempo está diretamente ligada à própria origem do vocábulo, que vem do grego khroniká, significando "relativo ao tempo".

A produção escrita constitui certamente uma das partes menos conhecidas da carreira de Tarsila do Amaral (1886-1973), uma das figuras centrais da arte brasileira no século XX. A artista dedicou muitos anos à sua coluna impressa, publicando seus textos semanalmente, acompanhando a vida social, política e cultural do país e suas transformações. As crônicas podiam ser divertidas ou sérias, mas nunca deixavam de apresentar um ponto de vista único.

Tarsila conferiu aos seus textos publicados em jornal propriedade informativa e crítica, ao invés de se limitar à linguagem da mera informação. Caracterizadas pelo diálogo ágil, pela narrativa curta e pela unidade de pensamento, as crônicas de Tarsila, muitas vezes, se "camuflavam" de conto. Tais escritos ora expunham a sua realidade contemporânea, ora voltavam-se ao seu passado, evocando memórias de suas viagens, especialmente as feitas a Paris. Nessa segunda categoria, literatura e história mesclam-se, compondo um hibridismo peculiar em seus textos. A diversidade da faceta cronista revela a erudição da artista, esculpida através de leituras e pesquisas.

A análise destes escritos, de um gênero considerado "menor" por Candido (1992, p. 13), pode recuperar o espaço intimista encontrado pela artista nas páginas do suporte jornal, elucidando diversos momentos de sua trajetória e suas impressões acerca dos mais variados temas, além de revelar aspectos da relação que ela mantinha com o público que a acompanhava.

Nesse sentido, o presente artigo propõe analisar o texto "Tragédia parisiense", publicado em 1937 pela artista plástica nos periódicos Diário de S. Paulo e O Jornal, acreditando que a autora utiliza o exercício da memória, através de diversas evocações e remissões ao passado, como interessante artifício de atração e envolvimento de seus leitores. Desse modo, verificamos a configuração autobiográfica a partir do tratamento do tempo e da reminiscência na crônica, em aproximação com a escrita de si como gênero literário. 
Ressaltamos que se preferiu, neste trabalho, manter a ortografia da época nas citações da crônica analisada, com transcrição consultada em número microfilmado do periódico $O$ Jornal disponível no repositório da hemeroteca digital da Fundação Biblioteca Nacional, objetivando uma melhor aproximação com a fonte primária.

\section{As mulheres e a imprensa}

A jornada pelo acesso à leitura, à escrita e à imprensa foi percorrida pelas mulheres, com grandes esforços e confrontos, para assegurar o seu direito à expressão e ao exercício da cidadania. Esse percurso inicia-se ainda no século XIX, com a emergência da mídia alternativa destinada exclusivamente a leitoras, através da publicação de jornais que debatiam questões relevantes à esfera familiar, às mudanças de costumes e à atuação das mulheres na sociedade e na política.

No Brasil, a participação de mulheres em jornais, com o passar das décadas, foi se tornando bastante significativa. Em paralelo ao surgimento de publicações escritas por homens voltadas ao público feminino, que tratavam de assuntos como moda, afazeres domésticos e culinária, nasciam espaços que contestavam a "condição do ser mulher". O novo posicionamento das mulheres por meio da imprensa indica, nas palavras de Pinto (2003, p. 33), a "existência de um incipiente movimento de construção de espaços públicos na sociedade brasileira e, no caso, por parte de pessoas que estavam completamente excluídas do campo da política e das atividades públicas".

Embora o registro do primeiro jornal feminino no país, intitulado O Jornal das Senhoras, date de 1 de janeiro de 1852 - editado pela argentina Juana Manso de Noronha (1819-1875) ${ }^{3}$, no Rio de Janeiro, no qual eram tratados temas como literatura, belas-artes e crítica cultural, áreas até então dominadas pela hegemonia masculina -, é importante frisar que, antes disso, já havia escritoras que contribuíam com os periódicos sob o disfarce de pseudônimos masculinos, abrindo caminhos para a imprensa feminina brasileira. Segundo Telles (1997, p. 337), elas primeiro tiveram de aceder à palavra escrita, em uma época em que se valorizava a erudição, mas lhes era negada educação que fugia às prendas domésticas, além de lerem o que sobre elas se escreveu para, assim, reverem a própria socialização e poderem reivindicar por seus direitos, publicarem, organizarem e fundarem jornais e revistas.

\footnotetext{
${ }^{3}$ Fundadora do Jornal da Senhoras, foi professora, jornalista, dramaturga e romancista em Buenos Aires, cidade onde nasceu. Viveu alguns anos no Brasil, onde atuou também como redatora de periódicos no Rio Grande do Sul e no Rio de Janeiro. Cf: MUZART (2003).
} 
De acordo com Ribeiro (2012), em busca de novas fatias de mercado, os periódicos, antes apenas informativos, mudaram seu formato e passaram a investir na publicação de outras seções, incorporando a função de entretenimento. Assim, nasceram os espaços destinados ao folhetim de variedades, à narrativa ficcional curta ou extensa, às cartas, às crônicas e também à poesia. Para os escritores, contribuir com os jornais tornou-se algo imprescindível, por proporcionar, além do abono financeiro, um elo direto com os leitores e maior notoriedade crítica.

Barbosa (2007) aponta que diversos autores, anônimos ou consagrados, usaram e abusaram do jornal para fazer circular seus escritos literários ou desenvolvidos em forma de literatura. Para ela, mesmo que questionemos a qualidade dessa produção, "não podemos perder de vista esse uso prático dos gêneros literários”, assim como não podemos deixar de reconhecer o suporte periódico como um "espaço plural, heterogêneo e fundamental na constituição de uma cultura letrada brasileira" (BARBOSA, 2007, p. 97). A autora aponta o jornal como um lugar da multiplicidade discursiva por excelência, revelando, ainda que de forma insipiente, as vozes dos mais variados segmentos da sociedade.

\footnotetext{
Expulsos da história literária, esses anônimos entram em cena a partir do momento em que os periódicos são tomados como suporte e fonte primária, por onde circulam várias vozes e vários discursos, em um pulsar heterogêneo e variado, que pode revelar múltiplas perspectivas de uma época e maneiras desiguais de se apropriar e de se aproximar da cultura escrita (BARBOSA, 2007, p. 40).
}

Seguindo essa perspectiva, as redações e grupos de leitores passaram aos poucos a congregar, além da elite masculina dos políticos-doutores-literatos, outros grupos, "como imigrantes, mulheres cultas da elite, camadas intermediárias letradas, professores, escrivães, caixeiros, funcionários burocráticos, tipógrafos e linotipistas - e também outros trabalhadores urbanos" (CRUZ, 2000, p. 80-81). A intromissão no suporte periódico destes setores sociais anteriormente alheios a seus códigos gerou diversas mudanças na cultura letrada tradicional. Saindo de um lugar eminentemente privado, as mulheres, principalmente as da elite, destacaram-se como notáveis personagens desse processo.

Eleutério (2005, p. 72-73) indica que seria impossível "dissociar o avanço da condição social da mulher das mudanças que lhe permitiram aspirar ao fechado sistema de produção intelectual na transição do Império para a República". Entretanto, podemos perceber que, se tal conjuntura propiciava-lhes ir além de seus tradicionais espaços sociais e intelectuais, 
possibilitando-lhes alguma autonomia cultural e trabalhista, também as cercaria de excessivas restrições e cuidados que regulavam sua conduta e arte.

De acordo com Duarte (2016, p. 14), mais do que os livros, "foram os jornais e as revistas os primeiros e principais veículos da produção letrada feminina", configurando espaços de aglutinação, divulgação e resistência. Ademais, em veículos não especialmente direcionados ao público feminino, "as folhas literárias abriam a possibilidade de convivência entre homens e mulheres no processo de escrita e de leitura dos periódicos", vinculando colunas "de variedades, de poesia, de moda, seções de culinária e de preceitos de economia doméstica” (CRUZ, 2000, p. 108).

$\mathrm{Na}$ conjuntura de grande parte das publicações, os padrões formais e eruditos da norma culta passaram a ser amenizados, e a linguagem jornalística incorporou progressivamente a oralidade. Cruz (2000, p. 111) indica que, no lugar das descrições áridas e pesados artigos, "entram quadrinhas, historietas, diálogos curtos e a crônica mais afeita ao linguajar do dia a dia”, procurando cativar o gosto dos novos públicos consumidores dos periódicos.

\section{As possibilidades da escrita de si no gênero crônica}

De acordo com Oliveira (2015), no Brasil, o gênero crônica não nasceu propriamente no interior do jornal, aparecendo, na verdade, em suas páginas quando este se tornou cotidiano ainda durante o século XIX, com tiragem relativamente grande e teor mais acessível. A crônica brasileira inicialmente era conhecida como folhetim de variedades, um "artigo de rodapé" sobre as questões do dia ou da semana (CANDIDO, 1992, p. 14-15). Foi por meio desse espaço que muitos autores puderam exercitar a escrita nos jornais, fosse ela de ordem narrativa, descritiva ou opinativa.

Para Candido (1992), a crônica herda do jornal a transitoriedade e o caráter efêmero, com os textos publicados nesse suporte morrendo diariamente, condenados ao consumo imediato e ao esquecimento. Nesse caso, o ambiente da notícia acaba também exercendo certa influência sobre o texto literário, determinando sua breve extensão e ligando-o diretamente a temas ou flagrantes do cotidiano retratado nas páginas da publicação periódica, ocasionando-lhe uma descontinuidade ou uma ausência de transcendência. Os assuntos seriam tratados por esse gênero através de uma linguagem aparentemente despretensiosa, mais próxima da conversa oral que da composição escrita, com “ar de coisa sem necessidade” (CANDIDO, 1992, p. 13). 
De acordo com Sá (1985, p. 10), a crônica seria "o registro do circunstancial” e o cronista, "narrador-repórter", um exímio observador de seu tempo, construindo divagações pessoais acerca de algum acontecimento banal ou importante. Ademais, o gênero também representa uma comunicação direta com o leitor, pautada em uma finalidade planejada, e não a simples transcrição de uma frase ouvida na rua (OLIVEIRA, 2015).

Já segundo Moisés (1978, p. 104), ao contrário de outros textos vinculados ao suporte periódico, a crônica deixou de lado a finalidade de apenas informar, mesclando elementos da literatura e da reportagem através de comentários subjetivos que recriam os fatos de sua contemporaneidade, assumindo um claro propósito de entretenimento, ainda que traga certo nível de informação em seu ínterim:

No entanto, o mais da crônica em que se localiza tal segmento livra-se da reportagem
pura e simples graças a outros ingredientes propriamente literários, dos quais é de
ressaltar o humor. Em toda crônica, por conseguinte, os indícios de reportagem se
situam na vizinhança, quando não mescladamente, com o literário [...] (MOISÉS,
1978, p. 248).

Ainda em consonância ao referido autor, o gênero crônica "move-se entre ser no e para o jornal", com o coloquialismo sendo-lhe elemento característico, por permitir a ambiguidade, a subjetividade e o diálogo direto com o leitor. Sá (1985, p. 21) complementa esse pensamento ao afirmar que o cronista agiria de maneira mais frouxa, dando a impressão de que "pretende apenas ficar na superfície de seus próprios comentários", desenvolvendo o tema como se fosse “ao acaso". O tom apressado de apreensão aparentemente imediata pautado no estilo simples esconderia possíveis artimanhas artísticas (OLIVEIRA, 2015).

A crônica se aproximaria da noção de biografema empregada por Roland Barthes (19151980), como uma espécie de microrrelato focado em pormenores, caracterizando um fragmento do autor:

O autor que vem de seu texto e vai para dentro da nossa vida não tem unidade; é um simples plural de 'encantos', o lugar de alguns pormenores tênues, fonte, entretanto, de vivos lampejos romanescos, um canto descontínuo de amabilidades, em que lemos apesar de tudo a morte com muito mais certeza do que na epopeia de um destino; não é uma pessoa (civil, moral), é um corpo (BARTHES, 2005 citado por FIGUEIREDO, 2013, p. 20).

Figueiredo (2013, p. 20) associa duas noções criadas por Barthes, a de biografema, na literatura, e a de punctum, na fotografia: “[...] não a completude de uma história, não a foto toda, mas pequenos detalhes, algumas inflexões, que emocionam numa biografia ou numa foto 
[...]”. Dessa maneira, como biografema, a crônica apresentaria um texto reduzido que possibilitaria a exposição de alguma lembrança pontual, de algum detalhe restrito.

Fidêncio (2011, p. 119) aponta que a autobiografia, assim como a crônica, no decorrer do tempo, nunca foi considerada um grande gênero pela crítica literária, mantendo "[...] com relação aos seus próprios paradigmas, aceitação, desconfiança, ou mesmo subversão".

[...] a autobiografia é um gênero que, como a crônica, foi situado ali à margem, ou à sombra dos gêneros literários, ou situado naquilo que seria mesmo a fronteira entre o ficcional desses gêneros literários e o não-ficcional ou referencial dos outros gêneros discursivos. Situado à margem da valoração positiva e às vezes até grandiloqüente com a qual gêneros literários, como o romance por exemplo, foram agraciados no decorrer do tempo (FIDÊNCIO, 2011, p. 119-120).

Gomes (2004, p. 12) elucida que o conjunto de modalidades que integram a escrita autorreferencial ou a escrita de si fundamentam-se na ideia "[...] que confere à vida individual uma importância até então desconhecida, tornando-a matéria digna de ser narrada como uma história que pode sobreviver na memória de si e dos outros". Tais textos assumiriam a subjetividade de seu autor "[...] como dimensão integrante de sua linguagem, construindo sobre ela a "sua" verdade" (GOMES, 2004, p. 14).

Lejeune (2008), ao principiar o estudo das narrativas autobiográficas, percebeu que elas constituem um campo literário indeterminado e impreciso, em que o leitor é provocado a realizar algum tipo de comprovação ou relação de verdade com o discurso do autor. Sendo assim, ele formulou a noção de "pacto autobiográfico", em que o narrador se assume como autor, estabelecendo a relação identitária entre autor, narrador e personagem: “[...] o que define a autobiografia para quem a lê é, antes de tudo, um contrato de identidade que é selado pelo nome próprio" (LEJEUNE, 2008, p. 33).

Finalmente, para Gomes (2004, p. 15), ante a escrita de si, o que passa a importar para o historiador (ou qualquer outro pesquisador), “[...] é exatamente a ótica assumida pelo registro e como seu autor a expressa", com o texto não dizendo o que houve, mas "[...] o que o autor diz que viu, sentiu e experimentou, retrospectivamente, em relação a um acontecido".

A escrita de si não se define, assim, como um gênero próprio que possui propriedades bem definidas e rigorosas; trata-se, antes, do caráter que determinado texto assume e que inclui escritos em primeira pessoa em geral. É uma variedade literária autobiográfica caracterizada pela tentativa do sujeito de objetivar o eu que fala. Essa narrativa ou relato do eu busca explorar, através da introspecção, o que representa e configura o indivíduo. Tal aspecto, muitas vezes, 
causa a identificação com o leitor, seduzindo sua atenção e garantindo a permanência desse tipo de escrita:

\begin{abstract}
Os diários, as memórias, as confissões pertencem a um gênero literário que sempre interessará à humanidade. Através deles a história se tem conservado palpitante de vida e de pitoresco. $\mathrm{O}$ autor, tomando parte ativa nas suas narrações, lhes dá um cunho de verdade que nos convence e satisfaz, mesmo que nelas entre uma dose de fantasia (AMARAL, 1943 citada por BRANDINI, 2008, p. 550).
\end{abstract}

Tarsila do Amaral, muitas vezes, tematizou suas lembranças em várias crônicas, apresentando aos leitores ocasiões importantes que viveu ou presenciou e ponderações acerca de expoentes da vida cultural que a cercava. Ganham destaque os textos dedicados a grandes nomes da intelectualidade e da arte, em que ela expunha o seu contato com o trabalho e a trajetória de tais figuras importantes.

\title{
O exercício da memória na crônica tarsiliana
}

Segundo Amaral (2001, p. 13-14), Tarsila do Amaral inicia suas atividades como cronista “[...] em pleno período de crise econômica de sua família, época da fazenda hipotecada, quando dividia seu tempo entre o Rio de Janeiro e São Paulo [...]”. Apesar de ter colaborado para o jornal $O$ Globo, em 1934, seu nome começa a aparecer regularmente na imprensa somente a partir de 1936, no periódico paulista Diário de S. Paulo, eventualmente também aparecendo na republicação de seus textos em $O$ Jornal, do Rio de Janeiro ${ }^{4}$.

Ainda de acordo com a autora (2003, p. 385), possivelmente por intermédio de seu amigo Assis Chateaubriand (1892-1968), magnata paulista fundador do conglomerado jornalístico Diários Associados ${ }^{5}$, a artista passou a assinar uma coluna inicialmente semanal com textos sobre arte e cultura, tornando-se "registradora de eventos, experiências e observações".

Tarsila vem nos demonstrar, mesclada com certa candidez diante da vida ou com uma doçura que a todos encantava, sua disponibilidade em manter vivo o interesse pelos acontecimentos, criações artísticas e mudanças ocorridas no país e no mundo. Por meio de suas crônicas ressalta, sobretudo, sua capacidade de recordar, com nostalgia e com precisão os momentos mais marcantes dos anos 20, de sua formação como pintora [...] (AMARAL, 2001, p. 13).

\footnotetext{
${ }^{4}$ As crônicas de Tarsila do Amaral foram catalogadas primeiramente por Amaral (2003) que, posteriormente, selecionou boa parte dos textos em uma reunião especial (2001). Mais recentemente, Brandini (2008) revisitou a coluna da artista plástica, republicando seus escritos integralmente.

${ }^{5}$ A intenção deste grupo, que incluía o Diário de S. Paulo e O Jornal, era modernizar os periódicos e imprimirlhes maior peso dentro do universo cultural brasileiro. A rede de comunicação entre os órgãos impressos justificava a republicação de textos de um jornal em outro.
} 
Fazendo o papel de mediadora e intérprete de acontecimentos diversos, a autora projetava nas crônicas seu largo conhecimento sobre história, literatura, música e artes plásticas no geral, chegando inclusive a lançar algumas linhas sobre o cenário político e as transformações da sociedade de então. Ademais, ela sempre deu destaque à notícia de suas viagens e ao encontro ou contato com artistas diversos, oferecendo comentários elucidativos sobre suas principais obras. Entretanto, toma destaque na coluna o registro do ordinário, para além da vida pública enquanto pintora famosa.

Em crônica publicada em 10 de dezembro de 1950 no periódico Fanfulla, às vésperas da mostra retrospectiva da artista plástica no Museu de Arte Moderna de São Paulo - MAM, Patrícia Galvão (1910-1926) traz algumas impressões acerca da autora, de quem fora discípula:

\footnotetext{
Ela me parece ser o nosso primeiro caso de "emancipação mental" entre as mulheres paulistas, e não por uma questão de riqueza, de formação intelectual, ou de viagem. Sacudida nas alturas de uma pretensiosa "high life" ou deixada no quadro modesto de um atelier de pintura, o sonho nas mãos, Tarsila do Amaral manteve o seu sorriso bom e acolhedor, a sua compreensão superior, a sua inteligência sempre aberta à Pesquisa, e com tudo isto uma dose de infinita modéstia, de esquivança nobre, nunca deixando de ser a primeira, mas fazendo tudo por que não o percebessem... (GALVÃO, 1950 citado por CAMPOS, 2014, p. 202).
}

O perfil traçado por Pagu revela uma mulher modesta e sonhadora por trás de uma inteligente antecipadora artística que refletiu o reconhecimento da capacidade criativa feminina no contexto brasileiro. Um detalhe pertinente seria o seu gosto pela pesquisa, o apego pelo conhecimento e o gosto por sua disseminação. Tal aspecto é retratado em seus textos, muitas vezes apresentados em tom de verbete, baseados em informações curiosas ou descobertas, frutos da leitura de diversos dicionários e enciclopédias.

O externar de opiniões é latente nos textos de Amaral, como no relevante "Feminilidade", em que a autora expõe sua opinião sobre a distinção entre o homem e a mulher na criação da arte: “[...] na pintura a mulher se iguala ao homem em técnica, supera-o no colorido, mas não o atinge na ousadia das concepções" (AMARAL, 1937b, p. 8). A crônica, publicada em 9 de junho de 1936 no Diário de S. Paulo e em 14 de junho de 1936 n'O Jornal, toma como ponto de partida uma citação do polêmico livro O homem, esse desconhecido (1935), do biologista francês Alexis Carrel (1873-1944), muito lido e discutido na década de 1940, em comparação com um comentário do pianista polonês Arthur Rubinstein (1887-1982) a respeito do trabalho 
da pianista brasileira Antonietta Rudge (1885-1974): "Gosto de Antonieta porque ela toca como uma mulher".

O texto de Tarsila revela um pensamento condizente com a ideia da feminilidade em meados do século XX, ainda atrelada a aspectos genéricos que lhe seriam inerentes, como a delicadeza e a sensibilidade: "O poder de abstracção no homem é superior ao da mulher. Mas a percepção sensitiva da mulher é muito mais apurada, assim como a sua intuição. O homem possue em mais alto gráo o espirito analytico, emquanto a mulher possue o synthetico" (AMARAL, 1937b, p. 8). Dessa maneira, para a cronista, a mulher de então não deveria procurar imitar as atitudes ou qualidades masculinas. Todavia, ela refuta a noção de hierarquia entre as posições de mulher e de homem, ressaltando que, diante das diferenças, um não pode ser inferior ao outro, pois um sempre possuirá características que o outro não tem:

\footnotetext{
A vida moderna pozá prova muitas aptidões femininas que permanecem desconhecidas nas épocas passadas. Falar da inferioridade da mulher, como geralmente se faz, é falar sem penetrar no sentido das palavras. O inferior presupõe o superior, e, entre o homem e a mulher tomados, cada um, como entidade differente, não póde haver uma comparação que estabeleça essa distincção (AMARAL, 1937b, p. 8).
}

Ao final da referida crônica, Tarsila concorda com a observação de Rubinstein sobre Rudge, apontando que ele a fez "o maior dos elogios" ao dizer que ela tocava piano "como mulher”. Tal passagem revela as contradições de uma época em que a posição social feminina atravessava grandes transformações.

Amaral (2001, p. 42-43) ressalta "o quanto de autobiográfico ou confessional é perceptível em trechos de suas crônicas", referindo-se ao caráter rememorativo de seus melhores anos em Paris, no registro de acontecimentos da cultura e da vida no Brasil, na referência a amigos ilustres ou a personagens desconhecidos dos leitores.

\footnotetext{
É sintomático que ao se iniciar como cronista Tarsila aborde primeiramente como temática as lembranças de sua vivência parisiense, como a desejar projetar e registrar suas memórias da década anterior, tão fundamental para sua vida e obra (AMARAL, 2001, p. 23).
}

Tarsila retornaria à capital francesa no início da década de 1930, já separada do escritor Oswald de Andrade (1890-1954) e atravessando tempos difíceis, principalmente no que diz respeito à vida financeira. De acordo com Amaral (2001, p. 31), na companhia do psiquiatra Osório César (1895-1979), seu companheiro na época, a artista passa por Paris na ocasião de 
ida e durante a volta de sua viagem à União Soviética, entre 1931 e 1932. É quando ela visita o antigo apartamento na Boulevard Berthier, momento lembrado na crônica "Tragédia parisiense", publicada em 23 de junho de 1937 no Diário de S. Paulo e em 27 de junho de 1937 n'O Jornal.

\begin{abstract}
Depois de um anno e meio de ausencia, Paris de novo. A ingenua alegria de rever, nos logares onde vivemos, um pedaço da nossa vida!

$\mathrm{O}$ grande salão do meu studio me esperava com fidelidade, me esperava como antigamente, todo atapetado, com seus móveis antigos e seus quadros modernos em perfeita harmonia. Bem bonito o meu salão! Sobre a estufa, as velhas porcellanas e os crystaes da Bohemia eram, deante de meus olhos esquecidos, presentes novos, bem amaveis (AMARAL, 1937, p. 8).
\end{abstract}

Em tom saudosista, a autora iniciava o texto remetendo à felicidade que sentira ao adentrar o seu estúdio na famosa avenida parisiense, sendo atenta à descrição de seus objetos, redescobertos aos poucos, "numa quasi infantil curiosidade" (AMARAL, 1937, p. 8). O texto foi escrito e publicado anos após a situação relatada, mas Tarsila parece bastante próxima do que narra, simulando o presente da escrita em sua narração. Ela recorda a tapeçaria, os móveis e os quadros, além das porcelanas e cristais que haviam sido preservados do mesmo modo que havia deixado por Madame Toussaint, apresentada como zeladora do prédio e viciada em “gorgetas bem brasileiras" (AMARAL, 1937, p. 8).

Conversando despretensiosamente com aquela senhora, a artista percebeu o quanto tinha permanecido afastada daquele lugar, sendo informada de que um dos filhos da cuidadora, Roberto, estava trabalhando nas construções em frente ao apartamento.

De facto, eu não conhecia mais o meu bairro. Do Boulevard Berthier, limitado por antigas fortificações - profundos vallos cuja inutilidade foi demonstrada durante a guerra moderna - surgiam agora, como num sonho, enormes blocos de apartamentos (AMARAL, 1937, p. 8).

Verificamos a interessante intersecção entre lembranças do cenário e reflexões acerca de sua então aparência contemporânea, que, aparentemente, já se demonstrava afetada pela acelerada modernidade e por eventos antecedentes à Segunda Guerra Mundial (1939-1945).

Tarsila segue a conversa com Toussaint, perguntando sobre seu rebento mais novo, René, a quem descreve como "rapazinho de 15 annos que ella adorava, apezar da sua preguiça, apezar da arrogancia com que a tratava e do pouco respeito para com os patrões, que, a cada passo, o botavam na rua" (AMARAL, 1937, p. 8). O retrato do jovem traz impressões bastante pessoais sobre o seu caráter, fazendo inferir que sua mãe tinha um amor enorme e incondicional por suas 
crias, detalhe que, mais tarde, se mostrará relevante à construção da crônica. Eis que, na resposta da zeladora, surge uma questão:

— O René agora está muito bom. Trabalha aqui perto, numa das casas de Felix Potin. Só o Fifi é que está muito mal.

Eu não me lembrava absolutamente do Fifi. Madame de Toussaint era viúva, moça ainda... Quem sabe? Não seria coisa do outro mundo o apparecimento de mais um filho (AMARAL, 1937, p. 8).

Temendo passar por mal-educada em decorrência do esquecimento da figura de Fifi, a autora informa-nos que liquidou o assunto comentando que aquilo não seria nada. Logo depois, dá um salto narrativo para o dia seguinte: "Paris descansava num domingo de sol. Junho. Sol sem calor, céu sem nuvens, alegria sem nodoas" (AMARAL, 1937, p. 8). A descrição nostálgica retrata a capital francesa em clima temperado, típico da primavera.

Todavia, a contemplação da autora é rápida, e ela logo retoma a contação de seu "causo" informando que havia ouvido de repente a lamentação de Madame Toussaint, acompanhada de seus filhos, pelo falecimento do tal Fifi. Ela, então, vê a oportunidade de expor suas impressões acerca do lar daquela família, fazendo alusão a outro momento do passado em que presenciou a mesma situação:

O appartamento de Madame Toussaint, no rez-do-chão, dava para um pequeno pateo. Era pequenino, escuro, mal visitado pelo sol. Em baixo um vestibulozinho donde subia uma escada para o andar superior. Esse aspecto, aquelle choro, lembraram-me imediatamente outra scena a que assistira quando morava, annos passados, numa velha casa ao lado do Boulevard de Clichy, num atelier de quinto andar, sem elevador, onde vivera o pae da pintura moderna, o celebre Cézanne. Nesse mesmo predio, a zeladora perdera uma filhinha, a Marguerite, creaturinha de 4 annos, que seria linda se tivesse um ar sadio. Mas como viver num quarto infecto, iluminado dia e noite por uma lâmpada electrica? Os parques de Paris, com suas velhas arvores, dão, é verdade, a esmola de um pouco de oxygênio á guryzada que brinca feliz. Marguerite, coitadinha, tinha que ficar ao lado da mãe. Então, a umidade, o mofo, o ar pestilento - inimigos silenciosos - foram vencendo, pouco a pouco, as mesquinhas resistências daquele organismozinho de quatro annos: um resfriado, complicações e a morte. A pobre mãe chorava sem consolo. Os vizinhos inundavam o quarto de flores (AMARAL, 1937, p. 8).

A lembrança da morte da menina Marguerite enlaça outras recordações interessantes, como a localização da moradia do pintor Paul Cézanne (1839-1906), cuja obra a artista estudou e comentaria em outra crônica mais tarde, em 1953. A autora ainda comenta sobre as árvores dos parques da capital francesa, acusando-as de, por serem velhas, não oferecerem tanto oxigênio às crianças. 
Voltando à cena lamuriosa de Madame Toussaint e seus filhos, já no fím da crônica, Tarsila a contrasta com a mencionada anteriormente: "Sobre uma mesa, jaz um cadaverzinho coberto por um lençól, entre flores e lagrimas" (AMARAL, 1937, p. 8). Ela aproxima-se do cortejo fúnebre comovida com a dor da chorosa mãe, sendo logo surpreendida:

— Quer vê-lo, Madame? ella me pergunta. Vai para junto da mesa e levanta o lençól. Fifi era um cachorro. Entre as suas patas dianteiras, bem juntinhas, estava collocado um ramo de flores (AMARAL, 1937, p. 8).

O desfecho inesperado coroa o tom cômico que vinha sendo esboçado desde o início do texto e pontuado em descrições divertidas como a dos marmanjos em prantos pela morte do cão-irmão: "Roberto gritava como um barytono de 18 annos e René completava o concerto doloroso". No final, percebemos que a curiosa tragédia parisiense que deu título à crônica serviu como subterfúgio para o exercício da memória de Tarsila do Amaral, justificando o manifestar de suas boas lembranças de Paris.

\section{Considerações finais}

Após a nossa análise, constatamos que a crônica constituiu um ambiente eficaz para que a artista Tarsila do Amaral manifestasse suas opiniões e recordações, envolvendo os seus leitores através de uma construção textual sólida e coesa. A autora soube aproveitar bem o espaço oferecido ao seu discurso por meio desse escrito de natureza híbrida dentro do jornal, conferindo notáveis comentários e tom ficcional aos seus relatos pessoais.

Mesmo com todas as limitações impostas às mulheres no suporte periódico, a crônica parecia proporcioná-la a liberdade para exprimir o que queriam do jeito que queriam. Com a utilização de uma linguagem mais coloquial e auxílio do discurso em primeira pessoa, Tarsila comprazia e atraía a atenção do público leitor.

Além disso, o estudo evidenciou o caráter dialógico da memória, que se movimenta em favor da narrativa, da contação do "causo", relacionando diferentes episódios preservados, diferentes imagens resguardadas. Isso evidencia não só as transformações decorridas do gênero escrita de si, mas a própria maleabilidade da literatura.

Em conclusão, Tarsila demonstra notável habilidade em confrontar seu texto com o tempo, com a reflexão de como se relacionava com ele. A cronista recorreu a biografemas em um aparente jogo entre a ficção e a autobiografia, entre a criação literária e a descrição de acontecimentos (através do registro memorialístico). Pensar nessa dinâmica é considerar as 
artimanhas da escrita, sobretudo a partir do modo como a autora, por meio da linguagem, se insere no processo de escrita de si.

\section{Referências}

AMARAL, A. Introdução: Tarsila cronista. In: AMARAL, A. Tarsila cronista. São Paulo: Edusp, 2001.p. 13-43.

Tarsila: sua obra e seu tempo. São Paulo: Editora 34, 2003.

AMARAL, T. Tragédia parisiense. In: O Jornal. Rio de Janeiro, 27 jun. 1937. Ano XIX, n. 5532. p. 8.

BARBOSA, S. F. P. Jornal e literatura: a imprensa brasileira no século XIX. Porto Alegre: Nova Prova, 2007.

BRANDINI, L. T. (Org.). Crônicas e outros escritos de Tarsila do Amaral. Campinas - SP: EdUnicamp, 2008.

CANDIDO, A. A vida ao rés do chão. In: CANDIDO, A. et al. A crônica: o gênero, sua fixação e sua transformação no Brasil. Campinas: Unicamp, 1992.p. 13-22.

CAMPOS, A. (Org.). Pagu: vida e obra. Companhia das Letras: 2014.

CRUZ, H. F. São Paulo em papel e tinta: periodismo e vida urbana-1890-1915. São Paulo: Educ/Fapesp/Arquivo do Estado de São Paulo/Imprensa Oficial de São Paulo, 2000.

DUARTE, C. L. Imprensa feminina e feminista no Brasil: século XIX - Dicionário ilustrado. Belo Horizonte: Autêntica, 2016.

ELEUTÉRIO, M. L. Vidas de romance: as mulheres e o exercício de ler e escrever no entresséculos (1890-1930). Rio de Janeiro: Topbooks, 2005.

FIDÊNCIO, L. M. Autobiografia ao correr da máquina: a escrita de si na crônica de Clarice Lispector. Dissertação [Mestrado em Letras]. Universidade Federal de Uberlândia UFU. Uberlândia - MG: 2011. Disponível em: <https://repositorio.ufu.br/bitstream/123456789/11823/1/D.pdf > . Acesso em: 17 mai. 2019.

FIGUEIREDO, E. Formas e variações autobiográficas. A autoficção. In: FIGUEIREDO, E. Mulheres ao espelho: autobiografia, ficção, autoficção. Rio de Janeiro: EdUERJ, 2013. p. 13-74.

GOMES, A. C. Escrita de si, escrita da história: a título de prólogo. In: GOMES, A. C. (Org.). Escrita de si, escrita da história. Rio de Janeiro: FGV, 2004. p. 7-24.

LEJEUNE, P. O pacto autobiográfico: de Rousseau à internet. Belo Horizonte: EdUFMG, 2008.

MOISÉS, M. A criação literária: prosa. São Paulo: Cultrix, 1978. 
MUZART, Z. L. Uma espiada na imprensa das mulheres no século XIX. In: Revista Estudos Feministas. CFH/CCE/UFSC. Vol. 11, n. 1, 2003. p. 225-233.

OLIVEIRA, V. V. Machado de Assis e os neologismos de Castro Lopes: reflexões linguísticas em crônicas de Bons Dias! Trabalho de Conclusão de Curso (Licenciatura em Letras). Universidade Federal da Paraíba. Departamento de Letras Clássicas e Vernáculas. João Pessoa: 2015.

PINTO, C. R J. Uma história do feminismo no Brasil. São Paulo: F. Perseu Abramo, 2003.

RIBEIRO, J. A. Literatura na imprensa. Goiânia: PUC-Goiás, 2012.

SÁ, J. A crônica. São Paulo: Ática, 1985. (Série Princípios)

TELLES, N. Escritoras, escritas, escrituras. In: PRIORI, M. del (Org.). História das mulheres no Brasil. São Paulo: Contexto; UNESP, 1997. p. 356-370.

Recebido em: 17/05/2019

Aceito para publicação em: 09/10/2019 